\title{
ATITUDES COOPERATIVAS DE DOCENTES EM AULAS DE EDUCAÇÃO FÍSICA NOS ANOS INICIAIS DO ENSINO FUNDAMENTAL
}

\author{
Sheila Aparecida Pereira dos Santos Silva \\ Universidade São Judas Tadeu, São Paulo, São Paulo, Brasil. \\ Inácio Inácio Brandl Neto \\ Universidade Estadual do Oeste do Paraná , Cascavel, Paraná, Brasil.
}

\begin{abstract}
Resumo: Tendências atuais em Educação vêm, cada vez mais, destacando os valores integrativos. Dentre eles, a atitude cooperativa é tida como essencial, principalmente por contribuir para a aprendizagem e para a convivência pacífica entre as pessoas. Com o objetivo de identificar os meios didáticos utilizados por docentes de Educação Física que atuam nos anos iniciais do Ensino Fundamental para o ensino e aprendizagem da cooperação como uma atitude permanente, foram observadas 54 aulas e descritas as atuações de três regentes de uma escola da cidade de Marechal Cândido Rondon - PR. Os resultados dessa pesquisa qualitativa e descritiva foram: 12 tipos de situações/atitudes cooperativas são utilizadas pelos professores, e as médias de ocorrências variaram entre 0,01 a 0,36 . Conclui-se que o propósito de desenvolver a atitude cooperativa parece ter sido incorporado pelas docentes estudadas, mesmo que tenham mostrado, em algumas situações, dificuldades para transpor suas intenções pedagógicas em ações didáticas. Isso destaca a importância dos processos de educação continuada e de apoio ao trabalho do professor como formas possíveis para minimizar tais dificuldades.
\end{abstract}

Palavras Chave: Educação Física, Ensino, Cooperação.

\section{Introdução}

O termo cooperação vem do latim cooperatione e significa ato ou efeito de cooperar que, por sua vez, é o ato de operar ou obrar simultaneamente; trabalhar em comum; ajudar; auxiliar; e colaborar (FERREIRA, 1997). Yus (2002, p.134) entende a cooperação "como a ação que se realiza em conjunção com outra pessoa ou pessoas para conseguir o mesmo fim". Brotto (2002, p.27) compreende cooperação como "um processo onde os objetivos são comuns, as ações são compartilhadas e os resultados são benéficos para todos". Para Almeida (2011, p.24), cooperação "significa agir em conjunto com o outro para resolver um problema ou alcançar um objetivo comum". Uma situação é cooperativa quando o objetivo de uma pessoa apenas pode ser alcançado quando todos os integrantes da situação alcançarem os seus, e uma atitude é cooperativa quando "o que A faz é simultaneamente benéfico para ele e para B, e o que B faz é simultaneamente benéfico para ambos" (BROTTO, 2002, p. 26).

Pesquisadores como os antropólogos Margaret Mead e Erich Fromm, que viajaram pelo mundo estudando os povos e suas culturas, constataram que as sociedades se organizam de formas diferentes e que tanto a competição como a cooperação são determinadas pela estrutura social de cada povo (BROTTO, 2002). Orlick (1989), doutor em psicologia da Universidade de Otawa (Canadá), chegou à mesma conclusão. Entre as várias formas de convivência, eles identificaram duas tendências: uma que classificaram como pacífica (cooperativa) e outra como destrutiva (hierárquica/agressiva/competitiva). 
Nas formas de convivência pacíficas não existiam hostilidades, violência, crueldade e punição rigorosa. Havia pouca competição, cobiça, inveja e individualismo. Acontecia muita cooperação e as crianças eram tratadas com amor e bondade. Nas formas de convivência destrutivas foram encontradas violência interpessoal, destrutividade, agressividade, malícia e crueldade; atmosfera de hostilidade, medo e tensão; excesso de competição; ênfase na propriedade privada e hierarquias rígidas (BROTTO, 2002).

Diante disso, perguntamos: qual dessas formas de convivência predomina na cultura brasileira? Para Capra (1996), a cultura ocidental está marcada pela ênfase nos valores autoafirmativos como expansão, competição, quantidade e dominação, em detrimento dos valores integrativos como conservação, cooperação, qualidade e parceria. Para Capra (1997) e Santos (2001), se dermos continuidade às formas de convivência competitivas de caráter destrutivo, poderemos colocar em risco a sobrevivência do ser humano e a do planeta e indicam as formas cooperativas como alternativas.

Orlick (1989) menciona que personalidades de destaque mundial como Mead, Montagu, Madre Teresa de Calcutá, alertam que a cooperação é essencial para as relações humanas e para a sobrevivência. Orlick (1989), Maturana (1998), Brotto (2002) e Soler (2002) afirmam que os seres humanos só sobreviverão se estiverem aptos a cooperar, a ajudar uns aos outros, a serem abertos e honestos e se preocuparem com os outros e com as novas gerações e que, se quiserem sobreviver e ter melhor qualidade é preciso se afastar da competição exacerbada.

O Relatório da Comissão Internacional sobre Educação para o Século XXI elaborado para a UNESCO (Delors, 1998) indica que a educação formal deve iniciar os jovens em projetos de cooperação, desde a infância, nos campos das atividades desportivas, culturais e sociais. Educadores como Piaget (1996), Freire (1996), Johnson, Johnson e Smith (1998), Sarabia (2000), Pozo (2002), González (2011) reconhecem a necessidade de incorporar o processo cooperativo na educação.

Na área da Educação Física (EF), Brotto (2002), Soler (2002), Amaral (2004), Batista (2006), Correia (2006), Almeida (2011) mostram como a cooperação pode estar presente em projetos de ação na escola e nas aulas.

Atualmente, a cooperação está presente em propostas curriculares na área da EF devido a principalmente duas razões: a) acredita-se que proporcionem mais e melhor aprendizagem dos discentes, devido ao conflito de opiniões e metas colocadas em conjunto; e b) acredita-se que promovem um benefício social, já que, normalmente, a interação entre os alunos acontece com entendimento, ajuda mútua, respeito, harmonia, de forma pacífica, tendendo a diminuir a violência (VYGOTSKY, 1996; POZO, 2002). Somam-se a estes aspectos a inclusão de todos no grupo e a participação efetiva, fatores que colaboram para o aumento da autoestima dos estudantes.

Tarefas educativas que envolvem valores cooperativos, que praticamente eram levadas a efeito apenas nos lares, nas igrejas e em outras instituições não-escolares, e passaram a ser realizadas na escola. Se verificarmos orientações curriculares recentes, observaremos finalidades como desenvolver a personalidade dos alunos de forma plena, formar para a paz, para a cooperação, para a solidariedade, para participar ativamente na vida social e cultural, para o respeito ao direito e liberdade fundamentais (SACRISTÁN, 2000).

Mas, que cooperação se quer? Saviani (2002) chama a atenção para ficarmos atentos e considerarmos nossos alunos como sujeitos históricos e culturalmente determinados, e estarmos alertas para que a aprendizagem cooperativa e a cooperação não sejam só meios eficazes de aumentar a produtividade para gerar lucros e reforçar as hierarquias. Para Bessa e 
Fontaine (2002), na aprendizagem cooperativa os objetivos devem estar mais voltados à autonomia, à responsabilidade, à formação cidadã e à possibilidade de intervenção na sociedade, e enfatizam que a escola pare de utilizar os tipos de ensino que reproduzem a hierarquia e a subordinação e optem em favor de ações de ensino orientadas para a ação coletiva e democrática dos alunos. Para eles, trata-se de substituir uma escola pensada como "fábrica/empresa", por uma escola inclusiva e capaz de desenvolver e promover indivíduoscidadãos, ao invés de produtores-consumidores.

Assim, a cooperação é proposta como uma alternativa/tentativa de melhorar a aprendizagem, o convívio social, amenizar a violência, superar o egocentrismo da criança, e levam a escola a atender sua função de formação humana e de promover indivíduos-cidadãos.

Em relação à EF, Correia (2006) entende que devido ao esporte ser um dos conteúdos principais e ser realizado de forma competitiva, existe a tendência de se repetir este modelo inclusive nas aulas dos anos iniciais do Ensino Fundamental.

A Associação dos Municípios do Oeste do Paraná (AMOP) lançou o "Currículo Básico para a Escola Pública Municipal” em 2007, atualizado em 2010. Esse documento explicita princípios pedagógicos e diretrizes curriculares norteadoras da ação dos professores da Educação Básica e, a partir de 2010, passou a enfatizar que a EF escolar trabalhasse com o objetivo de desenvolver a cooperação como uma "atitude permanente" que transpassa as práticas pedagógicas dos anos iniciais do Ensino Fundamental (do $1^{\mathrm{o}}$ ao $5^{\circ}$ ano). "É importante ressaltar o estímulo a atitudes cooperativas nas aulas de EF e para isso propõe-se o acréscimo de um novo conceito: atitudes permanentes, e deste conceito faz parte a cooperação" (AMOP, 2010, p.333).

Diante dessa proposta, indagamos: haveria esclarecimento suficiente dos docentes de EF a respeito do que se entende por atitude cooperativa e sobre como efetivá-la nas aulas? Os docentes de EF utilizam a orientação da AMOP para o desenvolvimento de atitudes cooperativas durante as aulas? Se utilizam, como o fazem? Qual seria a frequência com que o estímulo à atitude cooperativa ocorre nas aulas?

Entendemos que valorizar, ensinar e aprender cooperação são aspectos ainda não suficientemente pesquisados no cotidiano da EF escolar. Diante disso, o objetivo desta pesquisa foi identificar os meios didáticos utilizados por docentes de Educação Física que atuam nos anos iniciais do Ensino Fundamental para o ensino e aprendizagem da cooperação como uma atitude permanente.

\section{Método}

Essa pesquisa foi descritiva, de natureza quanti-qualitativa, com enfoque indutivo. No estudo descritivo com enfoque indutivo o pesquisador descreve o objeto de pesquisa e procura descobrir a frequência com que um fenômeno ocorre, sua natureza, características, causas, relações e conexões com outros fenômenos (BARROS e LEHFELD; 2000). Trata-se de um estudo qualitativo porque teve o ambiente natural como fonte das informações, um contato prolongado do pesquisador com o objeto da pesquisa durante o trabalho de campo, e observou aspectos qualitativos ligados a estratégias de ensino cooperativas utilizadas nas aulas (André, 2004; Oliveira; 2008) e a análise dos registros foi feita com base na frequiência com que as estratégias foram utilizadas.

Três docentes efetivos de uma escola da rede municipal de ensino do município de Marechal Cândido Rondon, estado do Paraná, foram os sujeitos da pesquisa.

A pesquisa foi autorizada pela Secretária Municipal de Educação e pela Coordenadora de EF. O critério para seleção da escola foi a presença do maior número de docentes de EF: três. A Diretora e as docentes receberam explicações sobre os objetivos da pesquisa, leram e assinaram o termo de 
consentimento livre e esclarecido. Esse estudo foi aprovado pelo Comitê de Ética da Universidade São Judas Tadeu, em São Paulo, sob o protocolo 082/2011.

As visitas à escola iniciaram no segundo semestre de 2011. Foram observadas aulas de anos (séries) diferentes, por considerarmos que, de acordo com a média de idade dos alunos de cada turma, poderiam haver diferenças nas situações e atitudes cooperativas observadas. Nove turmas foram selecionadas: duas da docente $\mathrm{A}\left(3^{\circ}\right.$ e $4^{\circ}$ anos), quatro da $\mathrm{B}\left(1^{\circ}, 2^{\circ}, 3^{\circ}\right.$ e $4^{\circ}$ anos $)$ e três da $\mathrm{C}\left(1^{\circ}, 2^{\circ}\right.$ e $3^{\circ}$ anos).

Sacristán e Gómez (1994), Martins (2001), Alves-Mazzotti (2001), André (2001, 2004) e Oliveira (2008), são unânimes em afirmar que a maneira mais eficaz de captar as informações no cotidiano escolar é a descrição, que pode ser acompanhada de outros meios auxiliares como filmagens, entrevistas e estudos documentais.

As aulas foram observadas visando identificar e quantificar oito tipos de situações cooperativas nas aulas: 1) situações de ajuda/cooperação são brincadeiras, tarefas, desafios e jogos em que as crianças necessitaram se ajudar/colaborar para realizar a tarefa/desafio/brincadeira/jogo, com ausência de competição (BROTTO, 2002); 2) situações com ajuda/cooperação competitiva são aquelas em que podem existir dois ou mais grupos tentando vencer uma brincadeira/jogo, porém todos os componentes do grupo devem participar e colaborar com seu grupo (ORLICK, 1989); 3) práticas participativas acontecem quando o método de ensino utilizado pelo docente é aberto à participação dos alunos para a tomada de decisões sobre a aula, por exemplo: regras das atividades, regras de convivência, opinião nas avaliações e brincadeiras, solicitar e explicar atividades (BECKER, 1994, 2001); 4) situações em grupo - com ajuda, cooperativa ou competitiva, são aquelas em que, simplesmente, os alunos necessitavam se ajudar (ORLICK, 1989); 5) situações-problema em grupos são as que contêm algum problema que os alunos deveriam resolver em grupo. Elas têm como características: apresentar um obstáculo (situação de impasse ou decisão da ação a ser realizada), fazer com que o aluno tenha melhor domínio da situação e do jogo, ser elaborada a partir de momentos significativos do jogo, e proporcionar aos participantes análises e questionamentos sobre como jogar, deixando de lado fatores como sorte e tentativa e erro (MACEDO, PETTY e PASSOS, 2000); 6) Metas decididas em conjunto acontecem quando professor e alunos combinam/decidem até onde chegar - quantidade, número de vezes (POZO, 2002); 7) pedidos de ajuda para buscar/recolher o material e 8) falação/orientação sobre ajuda/colaboração (SARABIA, 2000) são situações em que o professor orienta os alunos para colaborarem com a aula e com os colegas.

A forma de realizar os registros foi previamente testada em uma turma. Os procedimentos de análise e interpretação ocorreram "de forma interativa e acompanharam o processo de investigação" (ALVES-MAZZOTTI (2001, p.162). As anotações de campo foram digitadas e repassadas para as docentes para validação.

\section{Apresentação e Discussão dos Resultados}

O Quadro 1 ilustra as situações cooperativas observadas nas aulas por turma (ano) em que a aula foi observada e por professor (PA, PB, PC). Quatro tipos de situações cooperativas diferentes das descritas na literatura foram observadas e acrescentadas no Quadro 1, resultando em 12 (doze) tipos de situações cooperativas. Foram observadas 12 aulas da PA, 24 da PB e 18 da PC. Como o número de aulas observado por docente foi diferente, calculamos a média em que as situações cooperativas ocorreram para que fosse possível tecer comparações. No Quadro 1 constam a somatória em que as situações cooperativas foram observadas $\left(\sum\right)$ as médias observadas por professor e por turma com a qual trabalhou, e, na última coluna, a média de ocorrência de cada situação/atitude cooperativa no total de turmas observadas. 


\begin{tabular}{|c|c|c|c|c|c|c|c|c|c|c|c|}
\hline Turma & 10. & Ano & 20. & Ano & & 0. Al & & 40. & Ano & & \\
\hline Situações cooperativas/ professor & PB & $\mathbf{P C}$ & PB & $\mathbf{P C}$ & $\mathbf{P A}$ & $\mathbf{P B}$ & PC & $\mathbf{P A}$ & PB & $\sum$ & $\begin{array}{c}\text { Mé- } \\
\text { dia }\end{array}$ \\
\hline Em grupo - com ajuda & $\begin{array}{c}0,0 \\
8\end{array}$ & $\begin{array}{c}0,2 \\
2\end{array}$ & $\begin{array}{c}0,1 \\
7\end{array}$ & $\begin{array}{c}0,1 \\
1\end{array}$ & $\begin{array}{c}0,7 \\
5\end{array}$ & $\begin{array}{c}0,3 \\
3\end{array}$ & $\begin{array}{c}0,3 \\
9\end{array}$ & $\begin{array}{c}0,7 \\
5\end{array}$ & $\begin{array}{c}0,4 \\
6\end{array}$ & 56 & 0,36 \\
\hline Situações-problema em grupo & $\begin{array}{c}0,0 \\
8\end{array}$ & $\begin{array}{c}0,2 \\
2\end{array}$ & $\begin{array}{c}0,1 \\
7\end{array}$ & $\begin{array}{c}0,1 \\
1\end{array}$ & $\begin{array}{c}0,6 \\
7\end{array}$ & $\begin{array}{c}0,3 \\
3\end{array}$ & $\begin{array}{c}0,3 \\
3\end{array}$ & $\begin{array}{c}0,7 \\
5\end{array}$ & $\begin{array}{c}0,4 \\
2\end{array}$ & 53 & 0,34 \\
\hline Com prática participativa & $\begin{array}{c}0,0 \\
4\end{array}$ & $\begin{array}{c}0,1 \\
7\end{array}$ & $\begin{array}{c}0,2 \\
9\end{array}$ & $\begin{array}{c}0,2 \\
2\end{array}$ & $\begin{array}{c}0,5 \\
0\end{array}$ & $\begin{array}{c}0,1 \\
7\end{array}$ & $\begin{array}{c}0,3 \\
3\end{array}$ & $\begin{array}{c}0,7 \\
5\end{array}$ & $\begin{array}{c}0,2 \\
5\end{array}$ & 46 & 0,30 \\
\hline Com ajuda/cooperação & $\begin{array}{c}0,1 \\
3\end{array}$ & $\begin{array}{c}0,2 \\
2\end{array}$ & $\begin{array}{c}0,1 \\
7\end{array}$ & $\begin{array}{c}0,1 \\
1\end{array}$ & $\begin{array}{c}0,6 \\
7\end{array}$ & $\begin{array}{c}0,0 \\
8\end{array}$ & $\begin{array}{c}0,2 \\
2\end{array}$ & $\begin{array}{c}0,5 \\
8\end{array}$ & $\begin{array}{c}0,3 \\
3\end{array}$ & 42 & 0,28 \\
\hline Ajuda para buscar/recolher material & $\begin{array}{c}0,1 \\
7\end{array}$ & $\begin{array}{c}0,1 \\
7\end{array}$ & $\begin{array}{c}0,1 \\
3\end{array}$ & $\begin{array}{c}0,3 \\
3\end{array}$ & $\begin{array}{c}0,3 \\
3\end{array}$ & $\begin{array}{c}0,1 \\
7\end{array}$ & $\begin{array}{c}0,2 \\
2\end{array}$ & $\begin{array}{c}0,2 \\
5\end{array}$ & $\begin{array}{c}0,2 \\
1\end{array}$ & 36 & 0,22 \\
\hline Falação sobre ajuda/cooperação & $\begin{array}{c}0,1 \\
7\end{array}$ & 0 & $\begin{array}{c}0,4 \\
2\end{array}$ & $\begin{array}{c}0,1 \\
1\end{array}$ & $\begin{array}{c}0,4 \\
2\end{array}$ & 0 & $\begin{array}{c}0,1 \\
7\end{array}$ & $\begin{array}{c}0,2 \\
5\end{array}$ & $\begin{array}{c}0,1 \\
7\end{array}$ & 31 & 0,19 \\
\hline Com ajuda/cooperação competitiva & 0 & 0 & 0 & 0 & $\begin{array}{c}0,0 \\
8\end{array}$ & $\begin{array}{c}0,2 \\
9\end{array}$ & $\begin{array}{c}0,1 \\
1\end{array}$ & $\begin{array}{c}0,1 \\
7\end{array}$ & $\begin{array}{c}0,1 \\
3\end{array}$ & 15 & 0,09 \\
\hline Solicitação de ajuda aluno/aluno & $\begin{array}{c}0,1 \\
3\end{array}$ & $\begin{array}{c}0,1 \\
1\end{array}$ & $\begin{array}{c}0,1 \\
3\end{array}$ & $\begin{array}{c}0,0 \\
6\end{array}$ & 0 & 0 & 0 & 0 & $\begin{array}{c}0,0 \\
8 \\
\end{array}$ & 11 & 0,06 \\
\hline Solicitação de colaboração c/ outras turmas & 0 & $\begin{array}{c}0,1 \\
7\end{array}$ & 0 & 0 & 0 & 0 & 0 & 0 & 0 & 3 & 0,02 \\
\hline Metas decididas em conjunto & 0 & 0 & 0 & 0 & $\begin{array}{c}0,0 \\
8\end{array}$ & 0 & 0 & $\begin{array}{c}0,0 \\
8\end{array}$ & 0 & 2 & 0,02 \\
\hline Troca de papéis & $\begin{array}{c}0,0 \\
4\end{array}$ & 0 & $\begin{array}{c}0,0 \\
4\end{array}$ & 0 & 0 & 0 & 0 & 0 & 0 & 2 & 0,01 \\
\hline Ajuda prof/aluno na confecção de material & 0 & $\begin{array}{c}0,0 \\
6\end{array}$ & 0 & 0 & 0 & 0 & 0 & 0 & 0 & 1 & 0,01 \\
\hline Total & & & & & & & & & & $\begin{array}{c}29 \\
8\end{array}$ & \\
\hline
\end{tabular}

Quadro 1: Situações cooperativas observadas por ano e professor

As médias por ano foram calculadas para que fosse possível verificar se algum ano foi mais estimulado do que outro por meio de situações cooperativas, gerando o Gráfico 1 


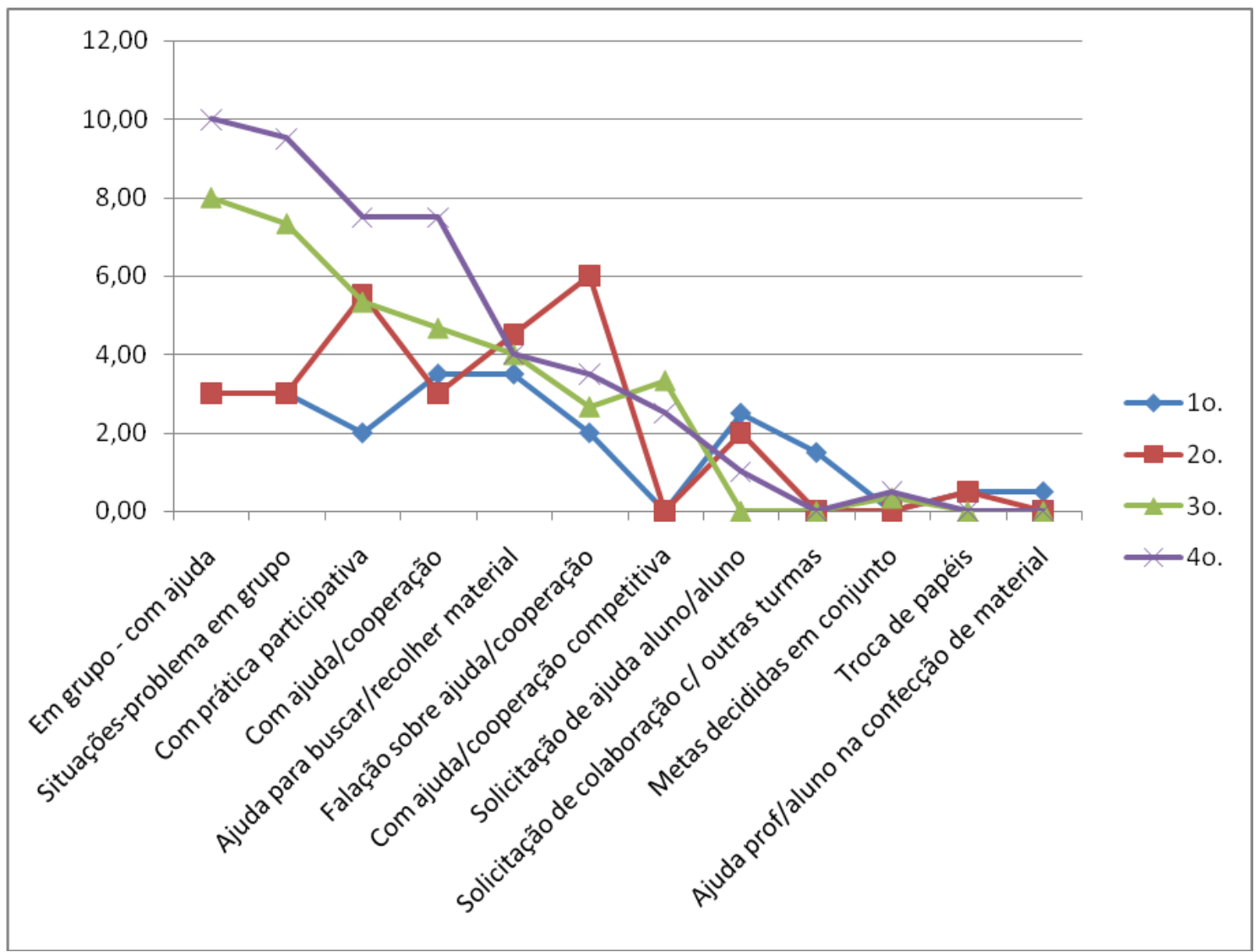

Gráfico 1 - Média de utilização de situações cooperativas por ano

O gráfico permite visualizar que, em geral, as turmas de $3^{\circ}$. e $4^{\circ}$. Anos vivenciaram situações cooperativas numa frequiência mais alta do que as turmas de $1^{\circ}$. e $2^{\circ}$. anos, ainda que a falação sobre ajuda/cooperação tenha apresentado número superior para essas turmas.

Durante as 54 aulas observadas foram registradas 298 ocorrências, dessas, apenas 15 incluíam algum tipo de competição (com ajuda/cooperação competitiva) e as demais 283 eram totalmente cooperativas.

As situações classificadas como em grupos com ajuda, situações-problema, prática participativa e com ajuda/cooperação, foram as mais utilizadas. Formas importantes de incentivar a cooperação como as metas decididas em conjunto, troca de papéis e a ajuda entre professor e aluno para confecção de materiais, aconteceram poucas vezes, talvez por falta de conhecimento das docentes.

Além das 8 (oito) situações descritas na literatura, observamos mais 4 (quatro) tipos: 1): troca de papéis; 2) solicitação de ajuda aluno/aluno; 3) confecção do material e 4) solicitação de colaboração com outras turmas.

Ocorre troca de papéis quando os participantes assumem o papel de outra pessoa ou colega com a finalidade de promover empatia e mudança de atitudes dos alunos (SARABIA, 2000).

A solicitação de ajuda aluno/aluno é entendida como uma atitude cooperativa porque incentiva a discussão, a colaboração e o entendimento entre as crianças, ensinando, aos poucos, os processos de autonomia, com a supervisão de um adulto (JOHNSON, JOHNSON e SMITH, 1998 e YUS, 2002). 
A confecção do material ocorreu apenas com a turma de $1^{\circ}$. Ano. Nós consideramos uma atitude cooperativa por que se trata de oferecer exemplo de ajuda a um colega quando este tem dificuldade para confeccionar um material para a aula.

Também entendemos a solicitação de colaboração com outras turmas como situação cooperativa, quando a professora solicitava silêncio e explicava que os colegas que se encontravam nas salas de aula podiam ser perturbados e prejudicados pelo barulho realizado nos corredores.

Com o objetivo de identificar se havia mudança na utilização das situações cooperativas de acordo com o ano em que as docentes trabalhavam, elaboramos o Gráfico 1.

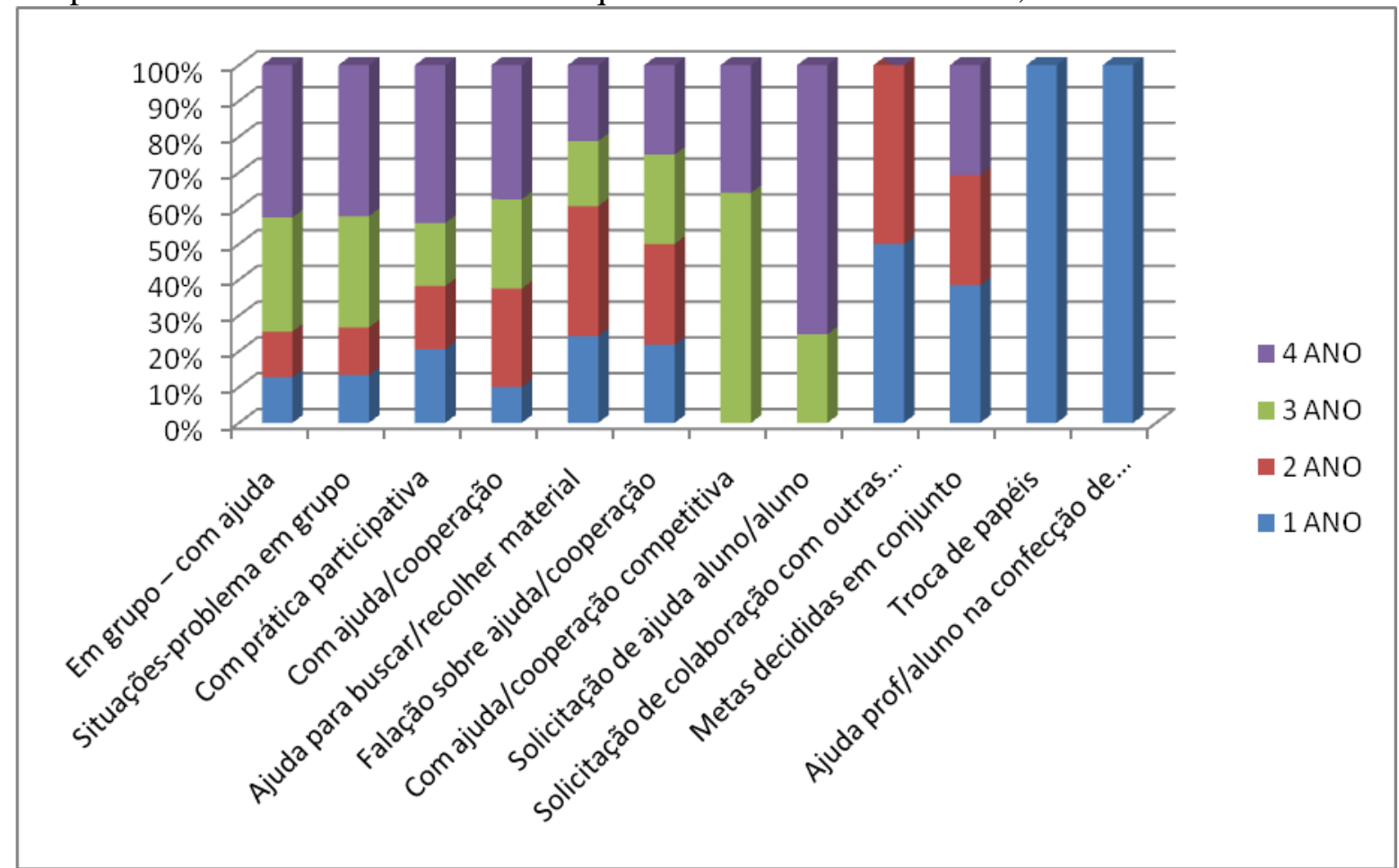

Gráfico 1 - Distribuição das situações cooperativas por ano

Nem todas as situações cooperativas foram observadas em todos os anos.

Todas as situações em que ocorreu a troca de papéis e o pedido de ajuda entre professor e alunos para a confecção de materiais ocorreram apenas nas turmas de $1^{\circ}$. Ano. A prática pedagógica com as turmas de $1^{\circ}$ ano foi mais diretiva, quando comparada com a prática efetivada com os demais anos. É comum que isso ocorra, pois as crianças ainda estão se ambientando com o meio e com a dinâmica escolar.

Em três situações houve vivências sociais com ajuda/cooperação em duplas e em pequenos grupos, como é o recomendado por Bee (1986) e Piaget (1996) para estimular a sociabilização.

Piaget (1996) e Araújo (1996) afirmam que, devido ao tipo de pensamento préoperatório e ao egocentrismo característicos de crianças com idades próximas aos seis anos, é difícil implementar atitudes cooperativas, mas reconhecem que não é impossível. Por isso, recomendam iniciar a aprendizagem cooperativa desde a pré-escola. A PB tentou seguir esta premissa, pois utilizou oito tipos de situações de estímulo à cooperação com a turma de $1^{\circ}$ ano. 
A solicitação de colaboração com outras turmas ocorreu apenas nas turmas de $1^{\circ}$. e de $2^{\circ}$. Anos.

Em uma das turmas de $2^{\circ}$ ano existiam problemas sérios de comportamento e aprendizagem, principalmente relativos à atenção. Diante disso, a professora de EF e a de sala combinaram de tentar realizar um atendimento diferenciado. Isso gerou ocasiões em que as crianças foram separadas em grupos menores para que houvesse muita conversa sobre o que estava acontecendo. Devido a essa peculiaridade, a ocorrência da falação sobre ajuda/cooperação foi uma situação bastante observada. Esse tipo de estímulo à atitude cooperativa ocorreu em todas as turmas e mostrando se tratar de uma estratégia valorizada pelas docentes pesquisadas.

A docente procurou fazer com que os alunos se envolvessem e dessem opiniões durante as orientações e atividades, como recomenda Sarabia (2000). Assim, recorreu às práticas participativas e utilizou a troca de papéis, porém sem o sucesso esperado já que nas situações fictícias propostas, nenhum aluno se dispôs a obedecer a outro.

Situações com ajuda/cooperação competitiva e solicitação de ajuda alunolaluno ocorreram apenas com as turmas de $3^{\circ}$. e $4^{\circ}$. anos; e a utilização das metas decididas em conjunto não ocorreram com as turmas de $3^{\circ}$. anos.

$\mathrm{O} 3^{\circ}$ ano foi a turma onde se observou mais competição. A PB sempre tomava cuidado para não valorizar o resultado dos jogos dizendo que o importante era que todos tinham brincado. Apesar da docente não valorizar verbalmente a competição ou o resultado das atividades, a maioria dos jogos teve este caráter.

Os fatores cooperativos observados durante oito situações em grupo e oito situações-problema ocorreram tanto internamente nas equipes que se defrontavam, como no comportamento individual de algumas crianças.

Como indica Sarabia (2000), para ultrapassar o egocentrismo e incentivar a reflexão, deveria haver mais discussões e questionamentos sobre as atividades e as situações cooperativas vivenciadas. Pode-se conjecturar que a dificuldade dos alunos compreenderem as situações cooperativas se deva à aprendizagem exclusiva das formas competitivas até o momento.

Para Piaget (1996), com crianças da faixa etária correspondente às turmas de $1^{\circ}$. ao $3^{\circ}$. ano deveriam vivenciar muitas situações cooperativas para ajudar a vencer o egocentrismo. A brincadeira/jogo totalmente cooperativo é um instrumento de auxílio poderoso, pois mostra, de forma concreta, as atitudes e valores que facilitam a convivência humana. A brincadeira/jogo são formas bastante ajustadas ao tipo de pensamento infantil, o que facilita a aprendizagem das atitudes e valores cooperativos.

$\mathrm{Na}$ turma do $4^{\circ}$ ano, as situações cooperativas e o incentivo a atitudes cooperativas foram mais freqüentes. Foram observadas três atividades competitivas, porém eram tão divertidas que não havia preocupação com a contagem de pontos. $4^{\circ}$. Ano. Percebemos que os conceitos específicos de cooperação propostos para as aulas poderiam ter sido mais e melhor discutidos.

Ao chegar ao $4^{\circ}$ ano, as crianças já acumulam uma série de vivências e um tipo de pensamento mais evoluído que nos anos anteriores, o que facilita trabalhar dessa maneira.

Seis entre doze situações cooperativas observadas foram vivenciadas pelas turmas de todos os anos: em grupo/com ajuda; situações-problema em grupo; com prática participativa; com ajuda/cooperação; ajuda para buscar/recolher o material e falação sobre ajuda/cooperação. Provavelmente essas são as estratégias para estimular a cooperação mais conhecidas pelas 
docentes e também as mais valorizadas, além de serem as que as docentes julgam estar mais adequadas às peculiaridades do comportamento infantil.

Piaget (1996), Vygotsky (1996) e Pozo (2002) preconizam que as intervenções pedagógicas devem ser iniciadas desde as mais tenras idades se o objetivo for promover mudanças efetivas no comportamento infantil. Em outras palavras, quanto maior o número de ações cooperativas as crianças observarem, perceberem e vivenciarem, maiores serão as probabilidades de ocorrência de mudanças de atitude em prol da cooperação.

De acordo com Sarabia (2000), não é suficiente ministrar atividades, deve-se ponderar, discutir, avaliar, refletir com os alunos os conceitos desenvolvidos nas aulas, e de preferência durante ou logo após as atividades, principalmente se forem crianças dos primeiros anos. Piaget (1996), Pozo (2000), Toledo, Velardi e Nista-Piccolo (2009), chamam a atenção dos professores para preconizarem atitudes, valores e juízos condizentes com condutas humanistas, dentro e fora da aula e, da mesma forma que Sarabia (2000), recomendam demonstrar e discutir estas condutas.

Orlick (1989) e Brotto (2002) sugerem outras maneiras de estimular as crianças para que percebam a ajuda/cooperação. O professor pode solicitar que as crianças representem ações cooperativas como colaboração/ajuda/solidariedade que realizaram nas aulas ou fora delas por meio de desenhos, recortes ou colagens. Outra forma sugerida seria colocar desenhos, fotografias, colagens nas paredes das salas de aula ou no pátio da escola, e promover gincanas ecológicas e outras em que os alunos tenham que se ajudar mutuamente.

Para promover mudanças mais efetivas de comportamento, Brotto (2002), Soler (2002) e Almeida (2003, 2011), argumentam que a escola e os pais também devem incentivar as atitudes cooperativas.

\section{Considerações Finais}

A pesquisa mostrou que existe certa dificuldade de operacionalizar os princípios pedagógicos ligados à cooperação, sugerindo que estes aspectos merecem mais investigação com vistas a serem desenvolvidas formas eficazes de capacitação docente, seja na formação inicial, seja na continuada.

A frequência com que as docentes promoveram situações propícias ao desenvolvimento da cooperação com as turmas de $1^{\circ}$ ao $4^{\circ}$ ano mostram que existe um esforço em estimular os alunos para a atitude desejada, muitas vezes superando o tabu de que tal trabalho não seria possível devido ao egocentrismo infantil.

Há de se considerar que, às vezes, a quantidade de ocorrências pode não indicar sua eficácia no desenvolvimento de atitudes cooperativas, sendo mais importante a qualidade e a profundidade com que as situações são vividas e significadas pelos estudantes.

Em nossa opinião, ainda que a quantidade de estímulos possa ser importante para incentivar atitudes cooperativas, o aspecto decisivo é a compreensão das situações vividas que se pode promover com os estudantes, trazendo à discussão como eles sentem e significam tais situações.

Ainda que se objetive o aprendizado da atitude cooperativa, a vivência e a aprendizagem que é promovida por meio de situações competitivas não devem ser descartadas. É interessante promover, progressivamente, formas cada vez mais elaboradas de discussões sobre ambas.

A partir dessas observações, foi possível inferir que as docentes procuraram utilizar as orientações contidas nas diretrizes da AMOP, promovendo em suas aulas a cooperação como 
uma atitude permanente. Estes resultados foram apresentados e discutidos com as docentes participantes do estudo como forma de feedback sobre seu desempenho didático e elas assentiram com as informações e análises, além de demonstrarem interesse em conhecer melhor o assunto. Com esse propósito, concordaram com a proposta de realização de futuros encontros para reflexões, discussões e relatos de experiências.

Em suma, este estudo evidenciou que o propósito de desenvolver a atitude cooperativa parece ter sido incorporado pelas docentes estudadas, mesmo que tenham mostrado, em algumas situações, dificuldades para transpor suas intenções pedagógicas em ações didáticas. Isso destaca a importância dos processos de educação continuada e de apoio ao trabalho do professor como formas possíveis para minimizar tais dificuldades.

A relação entre a competição e a cooperação ainda são temas que merecem mais estudos na área da EF e do Esporte, bem como pesquisas sobre a efetividade de estratégias didáticas para o desenvolvimento de atitudes e comportamentos.

\section{COOPERATIVE ATTITUDES OF TEACHERS IN PHYSICAL EDUCATION CLASSES IN THE EARLY YEARS OF BASIC EDUCATION}

Abstract: Current trends in education are increasingly highlighting the integrative values. Among them, the cooperative attitude is regarded as essential, primarily for learning and contribute to the peaceful coexistence between people. Aiming to identify the teaching methods used by teachers of Physical Education working in the early years of elementary school for the teaching and learning of cooperation as a permanent attitude, 54 lessons were observed and described the performances of three teachers in the city of Marechal Cândido Rondon - PR. The results of qualitative and descriptive research were: 12 kinds of situations /cooperative attitudes are used by teachers, and the average incidents ranged from 0.01 to 0.36 . The conclusion is that the purpose of developing the cooperative attitude seems to have been built by the studied teachers, even if they have shown, in some situations, difficulties to implement their pedagogical intentions in educational actions. This highlights the importance of continuing education processes and to support the work of teachers as possible ways to minimize such difficulties.

Key-words: Physical Education, Teaching, Cooperation.

\section{ACTITUDES COOPERATIVAS DE PROFESORES EN CLASES DE EDUCACIÓN FÍSICA EN LOS PRIMEROS AÑOS DE LA EDUCACIÓN BÁSICA}

Resumen: Las tendencias actuales de la educación están poniendo de relieve cada vez más los valores de integración. Entre ellos, la actitud de cooperación se considera esencial, sobre todo por su contribuición para el aprendizaje y para la convivencia pacífica entre las personas. Con el objetivo de identificar los métodos de enseñanza utilizados por los profesores de Educación Física que trabajan en los primeros años de la escuela primaria para la enseñanza y el aprendizaje de la cooperación como una actitud permanente, se observaron y describieron las actuaciones de tres profesores de una escuela de la ciudad de Marechal Cândido Rondon - PR en 54 clases. Los resultados de la investigación cualitativa y descriptiva fueron: 12 tipos de situaciones /actitudes cooperativas fueron utilizados por los profesores, y sus promedios oscilaron entre 0,01-0,36. La conclusión es que el reto de desarrollar la actitud cooperativa parece haber sido incorporado por las docentes estudiadas, aunque hayan mostrado, en algunas situaciones, dificultades para transponer sus intenciones pedagógicas para aciones didácticas. Eso destaca la importancia de los procesos de educación continuada y de apoio al trabajo del professor como formas posibles de disminuición de tales dificultades.

Palabras clave: Educación Física, Enseñanza, Cooperación. 


\section{Referências}

ALMEIDA, M.T.P. Jogos cooperativos e a transdisciplinaridade. In Almeida, M.T.P. (org.) Jogos cooperativos nos diferentes contextos. Várzea Paulista: Fontoura, 2011.

. Jogos cooperativos na Educação Física: uma proposta lúdica para a paz. III Congreso Estatal y Iberoamericano de Actividades Físicas Cooperativas. Gijón (Astúrias Espanha). Anais do Congresso, 2003.

ALVES-MAZZOTTI, A.J. O método nas ciências sociais; ALVES-MAZZOTTI, A.J.; GEWANDSZNAJDER, F. O método nas ciências naturais e sociais: pesquisa quantitativa e qualitativa. São Paulo: Pioneira Thomson Learning, 2001.

AMARAL, J.D. Jogos cooperativos. São Paulo: Phorte, 2004.

AMOP - Associação dos Municípios do Oeste do Paraná - Currículo Básico para a Escola Pública Municipal, Cascavel: Assoeste, 2010.

Associação dos Municípios do Oeste do Paraná - Currículo Básico para a Escola Pública Municipal, Cascavel: Assoeste, 2007.

ANDRÉ, M.D.A. Etnografia da prática escolar. Campinas: Papirus, 2004.

. A pesquisa no cotidiano escolar. In: Fazenda, M. (organizadora). Metodologia da pesquisa educacional. São Paulo: Cortez, 2001.

ARAÚJO, U.F. O ambiente escolar e o desenvolvimento do juízo moral infantil. In: MACEDO, L.(org.). Cinco estudos de educação moral. S. Paulo: Casa do Psicólogo, 1996.

BARROS, J.S.; LEHFELD, N.A.S. Fundamentos de metodologia: um guia para a iniciação científica. 2. ed.ampl. São Paulo: Makron Books do Brasil, 2000.

BATISTA, S.R. Os jogos cooperativos e a Educação Física Escolar. In MOREIRA, E.C. (org.). Educação Física Escolar: propostas e desafios II. Jundiaí: Fontoura, 2006.

BECKER, F. Educação e construção do conhecimento. Porto Alegre: Artmed, 2001.

BEE, H. A criança em desenvolvimento. São Paulo: Harbra, 1986.

BESSA, N.; FONTAINE, A. M. A aprendizagem cooperativa numa pós-modernidade crítica. Educação, Sociedade e Cultura, Porto, n. 18, 2002.

BROTTO, F.O. Jogos cooperativos. Santos: Projeto Cooperação, 2002.

CAPRA, F.O ponto de mutação. São Paulo: Cultrix, 1996.

. A teia da vida. São Paulo: Cultrix, 1997. 
CORREIA, M.M. Trabalhando com jogos cooperativos. Campinas: Papirus, 2006.

DELORS, J. Educação um tesouro a descobrir. Relatório para a UNESCO da Comissão Internacional sobre Educação para o século XXI. São Paulo: Cortez, 1998.

FERREIRA, A.B.H. Novo dicionário Aurélio da língua portuguesa. Rio de Janeiro: Nova Fronteira, 1997.

FREIRE, P. Pedagogia da autonomia. São Paulo: Paz e Terra, 1996.

GONZÁLEZ, A.E. Las competencias en la programación de aula. Barcelona: Graó, 2011.

JOHNSON, D.W.; JOHNSON, R.T.; SMITH, K. A. A aprendizagem cooperativa retorna às faculdades: qual a evidência que funciona? Change, v. 30, n. 4, jul./ago., 1998.

MACEDO, L.; PETTY, A.L.S.; PASSOS, N.C. Aprender com jogos e situações-problema. Porto Alegre: Artes Médicas Sul, 2000.

MARTINS, J. A pesquisa qualitativa. In: FAZENDA, M. (org.). Metodologia da pesquisa educacional. $7^{\mathrm{a}}$. ed. São Paulo: Cortez, 2001.

MATURANA, H. Da biologia à psicologia. Porto Alegre: Artes Médicas, 1998.

OLIVEIRA, M.M. Como fazer pesquisa qualitativa. Petrópolis: Vozes, 2008.

ORLICK, T. Vencendo a competição. São Paulo: Círculo do Livro, 1989.

PIAGET, J. Os procedimentos da educação moral. In: MACEDO, L. (org.). Cinco estudos de educação moral. São Paulo: Casa do psicólogo, 1996.

POZO, J.I. Aprendizes e mestres. Porto Alegre: Artmed, 2002.

SACRISTÁN, J.G.; GÓMEZ, A.I.P. Comprender la enseñanza en la escuela. Modelos metodológicos de investigación educativa. In: SACRISTÁN, J.G.; GÓMEZ, A.I.P. Comprender y transformar la enseñanza. $3^{a}$. ed. Madrid: Ediciones Morata, 1994.

SACRISTÁN, J.G. O currículo: uma reflexão sobre sua prática. Porto Alegre: ArtMed, 2000.

SANTOS, B.S. O norte, o sul e a utopia. In: SANTOS, B. S. (org.) Pelas mãos de Alice: o social e o político na pós-modernidade. São Paulo: Cortez, 2001.

SARABIA, B. A aprendizagem e o ensino das atitudes. In: COLL, C. et al. Os conteúdos na reforma: ensino e aprendizagem de conceitos, procedimentos e atitudes. Porto Alegre: Artmed, 2000. 
SAVIANI, D. Transformações do capitalismo, do mundo do trabalho e da Educação. In: LOMBARDI, I.; SAVIANI, D.; SANFELICE, J.L. (orgs). Capitalismo, trabalho e educação. Campinas: Autores Associados, 2002.

SOLER, R. Jogos cooperativos. Rio de Janeiro: Sprint, 2002.

TOLEDO, E.; VELARDI, M.; NISTA-PICCOLO, V.L. O que ensinar nas aulas de educação física. In: MOREIRA, E.C.; NISTA-PICCOLO, V.L. (orgs.). O que e como ensinar educação física na escola. Jundiaí: Fontoura, 2009.

VYGOTSTY, L.S. A formação social da mente. São Paulo: Martins Fontes, 1996.

YUS, R. Educação integral. Porto Alegre: Artmed, 2002.

Recebido em: 27/08/2014

Revisado em: 02/03/2015

Aprovado em: 13/03/2015

Endereço para correspondência:

sheila.silva@uol.com.br

Sheila Aparecida Pereira dos Santos Silva

Universidade São Judas Tadeu, Curso de Educação Física.

Rua Taquari, 546, Mooca

03166-000 - Sao Paulo, SP - Brasil 